ARCHIVO ESPAÑOL DE ARTE, LXXXVII, 345

ENERO-MARZO 2014, pp. 65-74

ISSN: 0004-0428, eISSN: 1988-8511

doi: 10.3989 /aearte.2014.05

\title{
VARIA
}

\section{CUERPO Y TORRES DE LA IGLESIA DE VILLACONEJOS ¿UNA NUEVA OBRA DE FRAY ALBERTO DE LA MADRE DE DIOS?}

\author{
JAVIER MARTínez RUIZ \\ Licenciado en Historia del Arte, Universidad Complutense de Madrid
}

\begin{abstract}
Argumentos que apuntan a fray Alberto de la Madre de Dios como tracista del cuerpo y torres de la iglesia de Villaconejos, partiendo de la documentación inédita de la obra.

Palabras clave: Iglesia de Villaconejos; Fray Alberto de Santa María; Fray Alberto de la Madre de Dios; Sebastián García de Huerta; Arquitectura clasicista; siglo XVII.
\end{abstract}

\section{THE MAIN BODY AND TOWERS OF THE CHURCH OF VILLACONEJOS A NEW WORK BY FRIAR ALBERT OF THE MOTHER OF GOD?}

Based on unpublished documentation, the author suggests that Friar Albert of the Mother of God is the architect of the main body and towers of the church of Villaconejos.

Key words: Church of Villaconejos; Friar Albert of Holy Mary; Friar Albert of the Mother of God; Sebastian García de Huerta; Classicist architecture; 17th century.

La iglesia parroquial de Villaconejos (Madrid), bajo el título de San Nicolás de Bari, es un templo prácticamente desconocido para la historiografía. Un simple vistazo aclara su proceso constructivo y encuadre estilístico, pero una mirada más atenta reconocerá el mérito e interés de su cuerpo y torres. Su tracista demuestra en ellos una considerable valía: la necesaria para superar el problema de cómo terminar una construcción ya comenzada con un planteamiento diferente al inicial, siendo el resultado final de un notable equilibrio de proporciones tanto en sus elementos, en la articulación de los mismos entre sí, como en la globalidad del conjunto; esto sólo puede conseguirse con una elevada cultura arquitectónica. El archivo parroquial de Villaconejos ${ }^{1}$ conserva una serie de documentos inéditos que precisan su cronología, sus campañas constructivas, sus artífices, etc. Entre sus noticias hay una que apunta a fray Alberto de la Madre de Dios

\footnotetext{
${ }^{1}$ Actualmente, el Archivo Parroquial de Villaconejos (en adelante APV), aún en la misma parroquia, se encuentra sin ordenar ni catalogar. Por tanto, lamentablemente, nuestras referencias documentales no podrán incluir los datos de localización en el archivo.
} 
como arquitecto de dichos cuerpo y torres. Este es el asunto fundamental en torno al cual giran estas líneas, porque se trata de una pequeña, pero interesante, aportación al conocimiento de la arquitectura de nuestro siglo XVII.

El actual templo parroquial de Villaconejos comenzó a levantarse en el segundo cuarto del siglo XVI sustituyendo a una iglesia anterior. La primera noticia que se conoce es de $1548^{2}$. Por entonces ya se había emprendido la obra del actual ábside poligonal según los patrones tardogóticos habituales: primero de mano de Juanes Garviria ${ }^{3}$; y, después, de la de los dos Martín de Ibarra, tío y sobrino ${ }^{4}$. Las tareas sufrieron paralizaciones y sólo pudieron terminarse, a duras penas, en 1598 con los trabajos de Miguel de Santiago; este maestro operó un profundo replanteamiento que configuró su actual interior clasicista ${ }^{5}$ siguiendo unas trazas y condiciones revisadas por Nicolás de Vergara el $\mathrm{Mozo}^{6}$. En ese estado se suspende la construcción del resto del templo, quedando el ábside unido al cuerpo de la vieja iglesia durante los siguientes treinta y tres años.

En 1628 se fechan las primeras referencias acerca de la empresa del cuerpo y torres que puso fin a la nueva fábrica parroquial. Todas las tramitaciones preparatorias para el contrato de esta obra se encuentran recogidas en un extenso documento que ofrece interesantes datos ${ }^{7}$. En él están copiadas cuatro provisiones del Cardenal Infante don Fernando, fechadas los días 18 de marzo y 17 de mayo de 1628, 8 de noviembre de 1630 y 3 de julio de $1631^{8}$; todas están dadas en Toledo, ciudad en la que el Cardenal Infante nunca estuvo9: en realidad eran enviadas por sus representantes en nombre suyo y para dar su aprobación, sin que implique su nombre una relación personal con la parroquia. Por tanto, don Fernando de Austria actúa como administrador perpetuo que era -desde 1619- del arzobispado toledano ${ }^{10}$, al cual pertenecía eclesiásticamente Villaconejos. Su relación con esta obra no parece que superase aquello que implicaba su condición de cardenal arzobispo primado. De hecho, en la misiva del 17 de mayo se informa de que el proyecto de finalización de la iglesia se retomaba a raíz de una "escriptura de concordia que se hiço entre el deán y cabildo de la Santa Yglessia de Toledo y el dicho Conçexo y particulares"l1 (de la villa de Villaconejos). Por tanto, deán y cabildo de una parte, y concejo de la villa y particulares de la otra, son los promotores de esta iniciativa.

Mientras que los tres primeros se presentan como personalidades institucionales concretas, los denominados "particulares" quedan sin especificar. El archivo parroquial de Villaconejos no tiene documentación directa sobre el asunto pero en este grupo puede ser incluido con total seguridad

\footnotetext{
2 MARÍAS Franco, 1983: vol. I, 301.

${ }^{3}$ Escritura con obligaçión para traer çien cahizes de arena para la obra de la capilla, 17 de febrero de 1549, APV, fol. 1r, 1-17.

${ }^{4}$ Fiança de la capilla que otorgó Martín de Ybarra y Juan Merino, 15 de febrero de 1558, APV. Poder de Martín de Ybarra, maestro, a Martín de Ybarra su sobrino para estar en todas sus obras, 17 de junio de 1559, APV. De ambos Ibarra se recogen datos de su actuación en la iglesia parroquial de Yepes (Toledo) en MARÍAs FrAnCO, 1986: vol. IV, 229-230.

5 Papeles de la obra de la capilla mayor, para cubrirla; y finiquito de la paga y cuentas, 1593-1619, APV: fol. $33 \mathrm{r}-37 \mathrm{v}$.

${ }^{6}$ Papeles de la obra de la capilla mayor,...: fol. 18v, 28-20r, 17.

${ }^{7}$ Escrituras del cuerpo y torres de la iglesia de Villaconejos, 8 de julio de 1631, APV. Se trata de un cuadernillo de 53 folios que contiene, grosso modo, estos puntos: informes de los maestros canteros de la obra (fol. 1r, 1-28v, 6); escrituras, provisiones del Cardenal Infante don Fernando, posturas y condiciones de la obra (fol. 28v, 7-41v, 16); pregones, remate de la obra y comunicado al Cardenal Infante (fol. 41v, 17-46v, 12); juramento de las dos partes contratantes: maestros canteros con sus fiadores y parroquia (fol. 46v, 13-53v, 21).

${ }^{8}$ Escrituras del cuerpo...: fol. 29v, 17-30v, 14; fol. 38v, 24-40r, 12; fol. 40v, 19-41v, 16; fol. 45r, 15-46r, 10.

9 Pérez Bustamante, 1935: 51.

10 SÁnchez Belén, 2010: 107.

11 Escrituras del cuerpo...: fol. 39r, 19-24.
}

Arch. esp. arte, LXXXVII, 345, ENERO-MARZO 2014, 65-74 ISSN: 0004-0428, eISSN: 1988-8511, doi: 10.3989/aearte.2014.05 
Sebastián García de Huerta (1576-1644) ${ }^{12}$. Sus vínculos con la parroquia fueron muy estrechos; sin estar muy claro el origen de tal relación parece que se debe a que sus raíces maternas estaban en Villaconejos ${ }^{13}$. Natural de La Guardia (Toledo), en 1607 el cardenal-arzobispo Sandoval y Rojas le nombra su secretario perpetuo de cámara; en 1616, Felipe III le nombra su secretario en el Real Consejo Supremo de la Santa y General Inquisición, perdurando como tal hasta su muerte; y en 1629, Felipe IV le nombra secretario de Su Majestad. Para nuestro estudio su figura cobra relieve en dos aspectos: las estrechas relaciones que mantenía con la Corona y su importante mecenazgo artístico ${ }^{14}$. Siendo el principal benefactor de esta iglesia en los años que nos ocupan, hay constancia de la donación de un cáliz aún conservado, una custodia, un terno blanco y unas andas ${ }^{15}$, además de un censo de doscientos ducados para la cofradía de San Nicolás y San Sebastián con cargo de oficios litúrgicos ${ }^{16}$. Su iniciativa o participación en esta obra, aunque muy probable, es mera hipótesis, mas sería un dato que podría explicar las trazas de fray Alberto de la Madre de Dios teniendo en cuenta sus lazos con el ambiente cortesano y su gusto artístico.

Pasemos ahora al asunto de la contratación de la obra. Los responsables de la parroquia dieron los primeros pasos efectivos el 4 de noviembre de 1630 con la recepción de la postura conjunta que tres maestros canteros habían presentado en Ocaña unos días antes, el 31 de octubre. Los interesados en encargarse de los trabajos fueron Íñigo de Lárez, Pedro de Gaña y Andrés Serrano. En ellos se remató finalmente el contrato el 6 de abril de $1631^{17}$. Entre los puntos de la postura y condiciones que habían presentado para encargarse de la labra del cuerpo y torres de la iglesia destacan los siguientes: "Nos obligamos de haçer la dicha obra por nueve mill ducados en ocho años, digo en siete años, en los quales la daremos acabada en toda perfeçión hasta dar las llaves en manos, conforme a la ttraça y condiçiones hechas por el padre fray Alberto de Santa María, sin exçeder, ni quitar, ni poner cossa alguna más de la dicha traça"; "Más, es condiçión que si pareziere tener alguna duda la planta y alçados y condiçiones, que para la declarazión de ellos pueda el cura y mayordomo nombrar maestro perito en el arte para que lo determine y declare; y por lo que declarare quedamos obligados a todo ello"18.

El nombre del autor de las trazas y alzados, fray Alberto de Santa María, mencionado cuatro veces a lo largo de todo el documento, va acompañado en tres de ellas de una observación: es carmelita descalzo ${ }^{19}$. Inmediatamente surge la pregunta, ¿no se tratará de fray Alberto de la Madre de Dios? La cuestión que se plantea es atractiva debido al significado, relevancia e, incluso, discusión que la figura de fray Alberto ha experimentado desde que Agustín Bustamante le atribuyese documentalmente La Real Encarnación de Madrid $^{20}$. Examinando la conjetura en nuestro caso, poco a poco se van encontrando diversos argumentos que apuntan a una respuesta afirmativa.

12 Mora Ontalva, 1987: 360-361. CAMPoy, 1923: 196-202.

13 CAMPOY, 1923: 200.

14 Ponz, 1791: XVI, 32-40. Campoy, 1923: 198-200. Mora Ontalva, 1963. Garrido Pérez, 2013: 56-68. BlanCo Mozo, 2002: 142-144.

15 Inventario parroquial, 1 de abril de 1652, APV: fol. 1r, 14-15, 23-24; fol. 2r, 12-14; fol. 4r, 17-18.

16 Libro IV de Memorias, 1769, APV: fol. 71v, 12-72r, 14.

17 Escrituras del cuerpo...: fol. 30v, 15-33r, 9; fol. 44r, 5-45r, 14.

18 Escrituras del cuerpo...: fol. 36r 5-19; fol. 37r, 3-16.

19 Escrituras del cuerpo...: fol. 25v, 19-23; fol. 31r, 20-23; y fol. 48r, 11-14.

${ }^{20}$ Bustamante García, 1975: 368-386. Habría que esperar hasta este descubrimiento a pesar de que Llaguno dijese de él que "era reputado en Madrid por gran arquitecto" (LLAGUNO Y AMIROLA, 1829: IV, 6); mucho más tarde seguiría siendo ignorado, aún cuando Nieto Gallo le destacase dentro de su intervención en Lerma (NIETO GaLlo, 1959: 21). Tras el artículo de Bustamante la cuestión de La Encarnación ha sido muy discutida (por ejemplo, Tovar MARTín, 1979: 85-96; 1983: 241-242), como también la valoración artística de fray Alberto (véanse los estudios de CeRVERA VERA) acompañada de diversos descubrimientos y atribuciones (nos remitimos a los estudios de José Miguel MuÑOZ JiMÉNEZ, en concreto a su monografía de 1990 y a la puesta al día que ofrece en los números 100, 109 y 121 de la revista Monte Carmelo).

Arch. esp. arte, LXXXVII, 345, ENERO-MARZO 2014, 65-74

ISSN: 0004-0428, eISSN: 1988-8511, doi: 10.3989/aearte.2014.05 


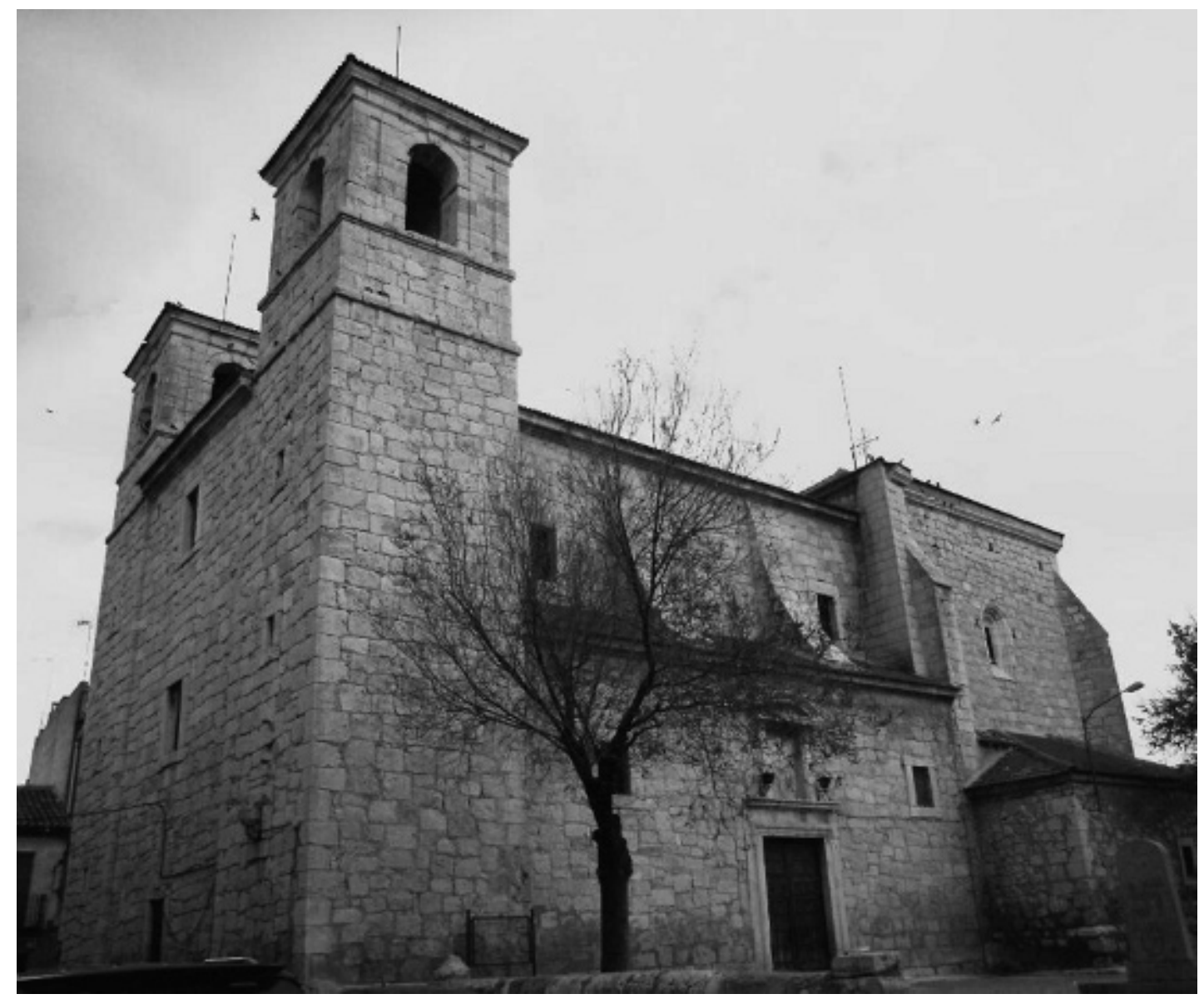

Fig. 1. Iglesia parroquial San Nicolás de Bari, vista general exterior, Villaconejos (Madrid).

Partimos de que comparten nombre y ambos son religiosos descalzos de la Orden del Carmen. Sólo parece que divergen en la advocación de sus nombres de religión: de Santa María y de la Madre de Dios. Esta aparente divergencia bien puede ser -y no es extraño- fruto de un error del escribano en uno de los primeros y originales escritos que se fue transmitiendo a los siguientes ${ }^{21}$. Por otro lado, a día de hoy, no se conoce ningún arquitecto carmelita con ese nombre. Muñoz Jiménez, uno de los mejores conocedores de la arquitectura del Carmelo y, en especial, de fray Alberto de la Madre de Dios, nunca se ha encontrado con fray Alberto de Santa María ${ }^{22}$. Por su parte, Verdú Berganza, en su tesis doctoral tampoco le conoce ${ }^{23}$.

${ }^{21}$ Dentro de la documentación del mismo APV encontramos errores de igual corte. Por ejemplo, en las escrituras del desaparecido retablo mayor de esta parroquia puede leerse "Valdeconexos" en vez de Villaconejos: De que ystoria de la yglesia de Villaconejos. Contra Françisco Esteban, pintor, 26 de marzo de 1605, APV: fol. 35v, 17. El error no se comprendería en el escribano de la propia villa, pero sí en Juan de Lezcanos que ejercía en la villa de Madrid.

22 MuÑoz JiMÉnEZ, 1990a; 1990b; 1992: 49-78; 2001: 479-489; 2013: 269-304.

23 Verdú Berganza, 1996.

Arch. esp. arte, LXXXVII, 345, ENERO-MARZO 2014, 65-74 ISSN: 0004-0428, eISSN: 1988-8511, doi: 10.3989/aearte.2014.05 


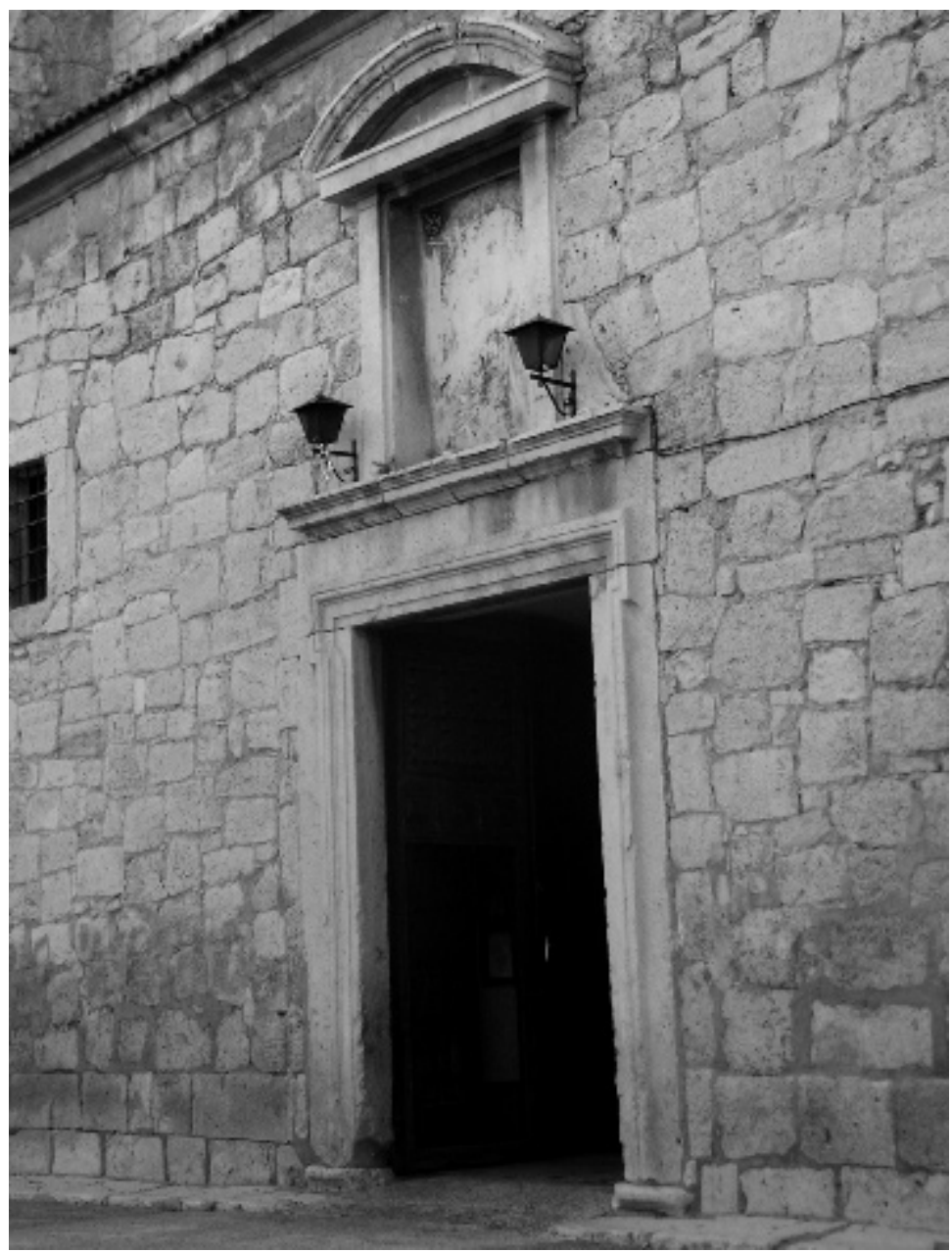

Fig. 2. Iglesia parroquial San Nicolás de Bari, portada meridional, Villaconejos (Madrid).

Aún se pueden añadir más indicios en relación con la actividad de fray Alberto en torno al año en que se pone en marcha la obra de Villaconejos, 1628. Fernando Marías, estudiando la presencia de fray Alberto de la Madre de Dios en Toledo, declara que las últimas noticias de su actividad en la ciudad son, precisamente, de 1628, cuando daba las trazas de la cripta de Andrés Pacheco, a construir en la parroquia de La Puebla de Montalbán (Toledo) ${ }^{24}$. Además, entre los años 1627 y 1629 estuvo al servicio de la Iglesia toledana visitando las obras de la iglesia parroquial de Getafe, no muy lejos de Villaconejos. Hay coincidencia cronológica pero, no obstante, hemos de tener en cuenta la posibilidad de que las trazas hubiesen sido dadas con anterioridad ya que en las aludidas cartas del Cardenal Infante don Fernando se pedía que no se retrasase más el cumplimiento de los acuerdos. ¿A cuánto tiempo podía referirse tal retraso? Tal vez a meses,

${ }^{24}$ Marías Franco, 1985: vol. II, 216-217.

Arch. esp. arte, LXXXVII, 345, ENERO-MARZO 2014, 65-74

ISSN: 0004-0428, eISSN: 1988-8511, doi: 10.3989/aearte.2014.05 
tal vez a años. En este último caso puede conjeturarse que los acuerdos retrasados se hubiesen realizado hacia 1626 cuando fray Alberto de la Madre de Dios, gozando de reputación en el cabildo toledano, daba informes sobre el Ochavo de su catedral e intervenía en otras fábricas ${ }^{25}$. En conclusión, por los años en que el cuerpo y torres que nos ocupan son trazados, fray Alberto frecuentaba Toledo al servicio de su orden y del cabildo ${ }^{26}$; en estas circunstancias, para solucionar la conclusión de la iglesia de Villaconejos, dicho cabildo acudió a un fray Alberto, carmelita descalzo que difícilmente sea otro que el célebre tracista de La Encarnación de Madrid.

A todo ello se suma el estudio estilístico del edificio. Ante todo, hemos de considerarlo enmarcado en la corriente predominante que diversos autores han denominado "Clasicismo"27. Esta arquitectura, de influjo palladiano, vignolesco y herreriano, tiene focos con personalidad propia: Valladolid, destacando Juan de Nates; Toledo, con Nicolás de Vergara el Mozo; e, incluso, una escuela carmelitana ${ }^{28}$. Se extiende por la segunda mitad del siglo XVI y permanecerá vigente en otro foco, el cortesano, hasta el fin del primer tercio del siglo XVII; aquí destacarán las creaciones de los discípulos y seguidores de Herrera, tales como Francisco de Mora, fray Alberto de la Madre de Dios, Juan Gómez de Mora ${ }^{29}$ y Alonso Carbonel ${ }^{30}$. El cuerpo y las torres de Villaconejos se encuadran en el clasicismo cortesano de fray Alberto con una marcada influencia de Francisco de Mora ${ }^{31}$.

En este contexto, el tracista de San Nicolás de Bari debía enfrentarse con el pie forzado que suponía el ábside. En efecto, ciñéndose a las proporciones de dicha cabecera proyecta una nave algo más estrecha, de tres tramos separados por pilastras y arcos fajones, con bóveda de medio cañón y lunetos; permite de este modo disponer capillas-hornacinas entre contrafuertes a cada lado de la misma sin sobrepasar los límites exteriores que marca el ábside. A los pies del templo dispone un severo hastial flanqueado por dos torres gemelas, entre las cuales, estrechando de nuevo la nave, sitúa un coro en alto sobre arco carpanel; bajo la torre septentrional ubica el baptisterio cubierto con bóveda semiesférica sobre pechinas y, en la torre meridional, la escalera para acceder al coro y a las cubiertas. Las portadas se abren enfrentadas en las capillas centrales; las ventanas, en las otras cuatro capillas, en los tramos de bóveda que coinciden con ellas y en la fachada occidental. El juego de volúmenes exterior expresa nítidamente el interior. En líneas generales se mantiene aún muy esencial, arquitectónico, sobrio, tal vez algo ajeno a la plasticidad que toman otras obras contemporáneas.

Visto todo el conjunto se puede afirmar que su tracista conocía y emulaba la iglesia de San Bernabé de El Escorial ${ }^{32}$, diseñada por Francisco de Mora corriendo el año 1589. Sin embargo, la iglesia de la villa escurialense tiene un antecedente vallisoletano en la iglesia de San Pedro Mártir de Medina de Rioseco, obra de Juan de Nates hacia $1580^{33}$, sobre todo en el modelo de nave con capillas laterales. Recuérdese que fray Alberto de la Madre de Dios -sin entrar a considerar el grado de dependencia o influencia- tuvo contactos con ambos arquitectos: en 1608 con Francisco de Mora en Lerma; y en 1613 con Juan de Nates en el diseño de la escalera del Cole-

\footnotetext{
25 MuÑOZ JiMÉNEZ, 1990a: 56-62.

${ }^{26}$ MuÑoz JiMÉNEZ, 1987: 111. Este historiador supone que fray Alberto fue llamado por dicha institución debido a la buena consideración en que ésta le tenía para la obra de la iglesia de Yunquera.

27 Bustamante García, 1983. Marías Franco, 1983. MuÑoz Jiménez, 1987: 29-30, prefiere denominarla "Manierismo clasicista".

28 MUÑOZ JiMÉNEZ, 1990b: 118-229.

29 Bonet Correa, 1961: 27-31. Tovar Martín, 1983: 67-214.

30 BlanCO MOZO, 2002: 652-654.

31 MuÑOZ JiMÉNEZ, 1990a: 78-81.

32 Cerviera Vera, 1943. Bustamante García, 1997.

33 García Chico, 1945: 191-194. Bustamante García, 1983: 228-233. 1997: 18-19.
}

Arch. esp. arte, LXXXVII, 345, ENERO-MARZO 2014, 65-74 ISSN: 0004-0428, eISSN: 1988-8511, doi: 10.3989/aearte.2014.05 


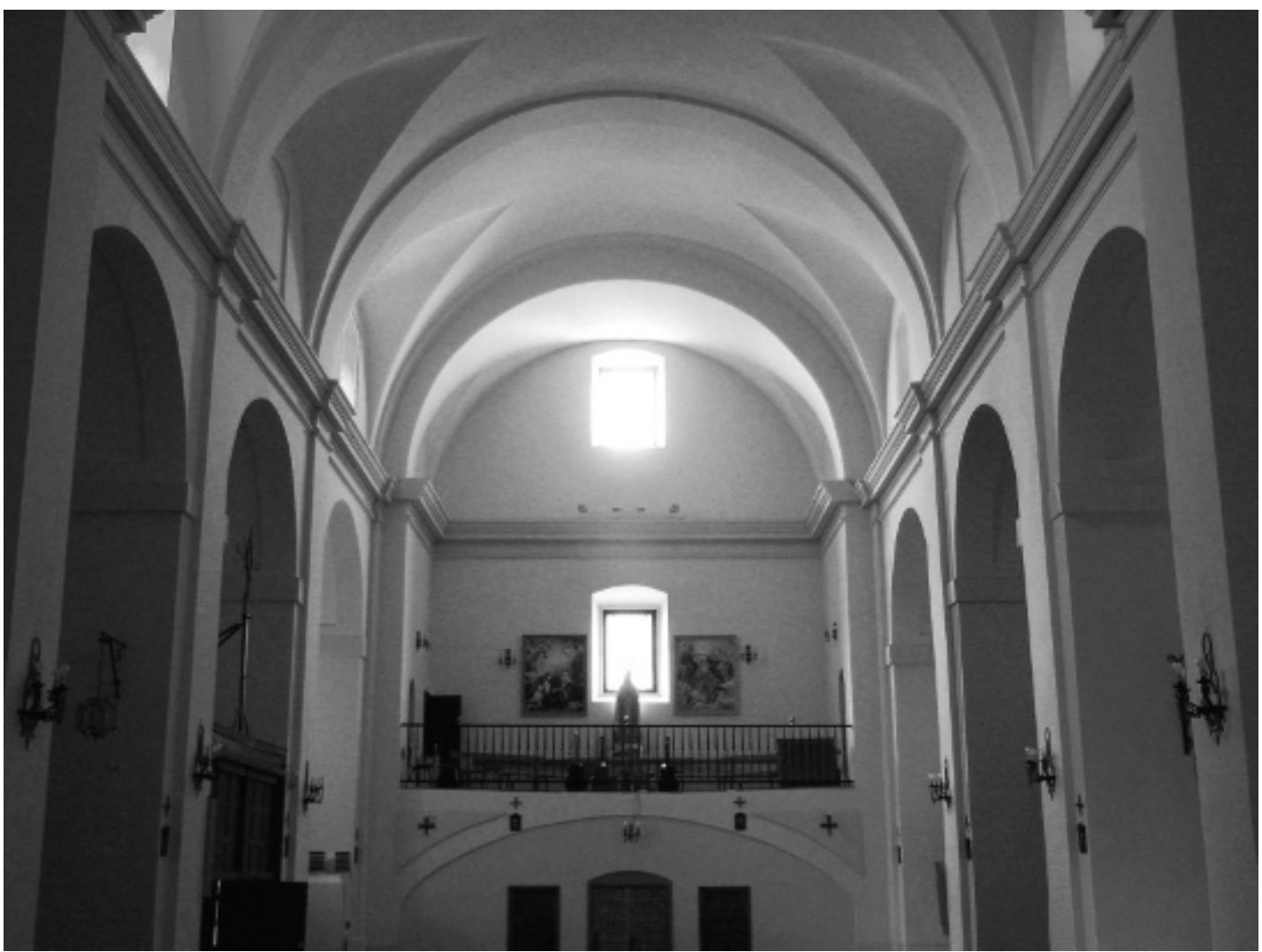

Fig. 3. Iglesia parroquial San Nicolás de Bari, vista de la nave hacia los pies, Villaconejos (Madrid).

gio de Santiago de Salamanca ${ }^{34}$. Sin embargo, cotejando las tres iglesias, es evidente que la globalidad del cuerpo y torres de Villaconejos tiene como modelo al templo de El Escorial de Abajo; de él toma planta, alzados interiores y exteriores, distribución de espacios (coincide, por ejemplo, la organización de los pies con coro entre las torres, baptisterio con dos entradas en la torre norte y escaleras en la sur), diseño de campanarios (en ambos casos con la mejor fábrica de la construcción, en excelente sillería), etc.

A pesar de lo dicho, hay algunas diferencias entre ambos que responden a los condicionantes propios del templo de Villaconejos. Efectivamente, la esbeltez del cuerpo y torres que nos ocupan contrasta con las proporciones del templo escurialense debido, como se manifestó, a las medidas del ábside: éste obliga a estrechar la nave y, consecuentemente, resultan unos alzados más erguidos, unas capillas equitativamente más grandes en planta, un coro en alto más ancho y más unido a la nave, y una fachada y torres más altivas. Otra diferencia que puede explicarse es la disposición de las portadas. En San Bernabé se encuentran en la capilla central del mediodía y en la fachada occidental; en Villaconejos se mantiene la entrada meridional en la capilla central, pero la puerta principal entre las torres parece haber sufrido un traslado. Resulta muy extraño que no se disponga en el hastial torreado como es norma, ya que las torres cobran sentido monumen-

34 Llaguno y Amirola, 1829: IV, 7.

Arch. esp. arte, LXXXVII, 345, ENERO-MARZO 2014, 65-74

ISSN: 0004-0428, eISSN: 1988-8511, doi: 10.3989/aearte.2014.05 
talizando la entrada principal. Tal vez las circunstancias urbanísticas hicieron plantearse tal cambio a fray Alberto en las mismas trazas o a los responsables de la parroquia durante los trabajos: como la puerta principal iba a abrirse a una calle menor y sin posición destacada, la trasladaron a la fachada septentrional, a la calle principal de la villa, aun perdiendo una capilla e, inevitablemente, una fuente de ingresos. Dichas portadas siguen un mismo modelo: vano de entrada adintelado, enmarcado por una moldura con orejeras en los ángulos superiores y una cornisa por remate; sobre ella surge una amplia y sencillísima hornacina rectangular con frontón curvo. Son plenamente albertianas y muy similares a las portadas de los conventos de San José de Medina de Rioseco y de Ocaña, del convento de Valdemoro, etc.; las hornacinas, por su parte, son semejantes a las de La Encarnación de Madrid y a las de las carmelitas y dominicas de Lerma.

Otras diferencias se deben a lo que Tovar Martín afirma acerca de la arquitectura del siglo XVII: que se mueve entre el respeto y admiración por el legado escurialense y la innovación personal de los $\operatorname{artistas}^{35}$. En la arquitectura de fray Alberto de la Madre de Dios puede apreciarse una tendencia unificadora que contrasta con la neta diferenciación de líneas y volúmenes que busca Mora en sus diseños. Esto se plasma en la versión que del modelo de San Bernabé se hace en Villaconejos. En primer lugar puede advertirse esta inclinación del carmelita en la solución del entablamento interior toscano: mientras que en la iglesia de Mora éste es corrido y el capitel de las pilastras se funde con él ${ }^{36}$, en nuestro caso el entablamento rompe su continuidad adaptándose a la planta de las pilastras, cuyo capitel ha desaparecido. Al exterior, los estribos de El Escorial son recios contrafuertes rectangulares, mientras que en Villaconejos son discretos aletones que suavizan el paso entre el plano inferior y el superior de las fachadas laterales. La fachada de El Escorial presenta dos planos, cuerpo avanzado entre las torres y frontón ${ }^{37}$, mientras que la de Villaconejos, eliminando el frontón, ha quedado unificada (lo mismo sucede en La Encarnación de Madrid, donde fray Alberto ha unificado el modelo en dos planos que Mora diseña en San José de Ávila ${ }^{38}$ ). Respecto al diseño del cuerpo de campanas de las torres fray Alberto ha tomado el esquema de los de Francisco de Mora pero se ha alejado de su depurado geometrismo otorgándole una mayor plasticidad. En definitiva, todas estas innovaciones respecto a la herencia herreriana recibida, son las mismas que pueden verse en la última arquitectura de fray Alberto de la Madre de Dios, especialmente patentes en el paso adelante que dio en 1632 con la iglesia de los Santos Reyes de Guadalajara ${ }^{39}$.

Este análisis formal de la iglesia de San Nicolás de Bari define sus parentescos con las obras de línea cortesana de fray Alberto de la Madre de Dios. Si es cierta la autoría de fray Alberto de la Madre de Dios esta creación queda contextualizada entre las trazas del convento de San José de Toledo y de San Alberto de Ocaña (1626), del convento de San José de Cuenca y la cripta de Andrés Pacheco en La Puebla de Montalbán (1628), de la capilla de Nuestra Señora del Sagrario en la catedral de Cuenca (1629), de la colegiata de Pastrana y del convento de los Santos Reyes de Guadalajara (1632), y de las bóvedas de la cabecera de la iglesia de Yunquera de Henares (1633). Asimismo, se trataría de uno de los pocos ejemplos de iglesia parroquial del carmelita ${ }^{40}$ con una traza muy alejada de su quehacer habitual; en esta ocasión, fray Alberto habría resuelto

35 Tovar Martín, 2002: 287.

36 Bustamante García, 1997: 20.

37 Bustamante García, 1997: 21.

38 MUÑOZ JiMÉNEZ, 1990b: 158.

39 MuÑoz JiMÉNEZ, 1989b: 84-86.

40 MuÑoz JimÉNEZ, 1990a: 65-71. En Yunquera de Henares únicamente debía abovedar un espacio ya determinado. MuÑoz JiméNEZ, 2013: 273-274. En la parroquia de Montilla de Palancar (Cuenca) se trataba de completar las tres naves, mientras que en la iglesia de Gascueña (Cuenca) traza la capilla mayor.

Arch. esp. arte, LXXXVII, 345, ENERO-MARZO 2014, 65-74 ISSN: 0004-0428, eISSN: 1988-8511, doi: 10.3989/aearte.2014.05 
el problema de cómo terminar la parroquia de Villaconejos recurriendo a un modelo creado por Mora casi cuarenta años atrás; si ello le restase originalidad, habría que resaltar lo afortunado y perfecto de la adaptación al ábside, además de su propia interpretación y avance respecto al precedente señalado. Al mismo tiempo, se podrían replantear las relaciones entre ambos, que han sido definidas tanto de maestro-discípulo, como de meros colegas de gremio.

Al ultimar estos razonamientos queda demostrado que todo lo apuntado, partiendo del nombre que recoge la documentación, concuerda con la situación, ambiente y arquitectura de fray Alberto de la Madre de Dios; todo menos el "de Santa María" que, como dijimos, creemos se trata de un error de escribanía. Por ende, ¿pueden desaparecer los signos de interrogación que abren esta exposición? Si la respuesta negase que se trata de fray Alberto de la Madre de Dios, un tracista nuevo saldría a la luz documentalmente, fray Alberto de Santa María, del cual, a la vez, conoceríamos una interesante obra. Habrá que convenir, al fin, que este artículo sólo puede reconocerse como punto de partida para una investigación que resuelva estos interrogantes.

\section{BIBLIOGRAFÍA}

Blanco Mozo, Juan Luis, Alonso Carbonel (1583-1660), arquitecto del Rey y del Conde-Duque de Olivares (tesis doctoral), Madrid, Universidad Autónoma de Madrid, 2002. (Editado por Fundación Universitaria Española, Madrid, 2007).

Bonet Correa, Antonio, Iglesias madrileñas del siglo XVII, Madrid, CSIC Instituto Diego Velázquez, 1961.

Bustamante García, Agustín, "Los artífices del Real Convento de La Encarnación, de Madrid”, Boletín del Seminario de estudios de Arte y Arqueología, XL-XLI, Valladolid, 1975, pp. 369-388.

Bustamante García, Agustín, La arquitectura clasicista del foco vallisoletano (1561-1640), Valladolid, Institución Cultural Simancas, 1983.

Bustamante García, Agustín, "La iglesia de El Escorial”, Boletín del Museo e Instituto "Camón Aznar”, LXVII, Zaragoza, 1997, pp. 5-39.

Campoy, José María, "El Secretario Huerta”, Boletín de la Real Academia de Bellas Artes y Ciencias Históricas de Toledo, 17-18, Toledo, 1923, pp. 196-202.

Cervera Vera, Luis, "La iglesia parroquial de San Bernabé en El Escorial, obra de Francisco de Mora", Archivo Español de Arte, XV, Madrid, CSIC, 1943, pp. 361-379.

Cervera Vera, Luis, El conjunto palacial de la villa de Lerma, Valencia, Editorial Castalia, 1967.

Cervera Vera, Luis, El monasterio de San Blas en la villa de Lerma, Valencia, Editorial Castalia, 1969.

Cervera Vera, Luis, La Iglesia Colegial de San Pedro de Lerma, Burgos, Caja de Ahorros Municipal de Burgos, 1981.

García Chico, Esteban, La ciudad de los Almirantes. Su historia y tesoro artístico, Valladolid, 1945.

Garrido Pérez, María del Carmen, "Velázquez y el Inquisidor", Ars Magazine: revista de arte y coleccionismo, 17, Madrid, 2013, pp. 56-68.

Ibáñez Martínez, Pedro Miguel, "Arquitectura, clima y topografía: el carmelita fray Alberto en Cuenca", Boletín del Museo e Instituto “Camón Aznar”, LXXXIV, Zaragoza, 2001, pp. 81-106.

Llaguno y Amirola, Eugenio, Noticias de los arquitectos y arquitectura de España desde su restauración, IV, Madrid, Imprenta Real, 1829.

Marías Franco, Fernando, La arquitectura del Renacimiento en Toledo (1541-1631), 4 vols., Toledo, Publicaciones del Instituto provincial de investigaciones y estudios toledanos, 1983-1986.

Mora Ontalva, José María, "Noticias sobre las obras de arte de la iglesia de La Guardia", Archivo Español de Arte, XXXVI, Madrid, CSIC, 1963, pp. 65-72.

Mora Ontalva, José María, "Sebastián García de Huerta”, en Aldea Vaquero, Quintín. Marín Martínez, Tomás. Vives Gatell, José (dirs.), Diccionario de Historia Eclesiástica de España, suplemento I, Madrid, CSIC Instituto Enrique Flórez, 1987, pp. 360-361.

Muñoz Jiménez, José Miguel, "El arquitecto carmelita fray Alberto de la Madre de Dios (1575-1635) en Guadalajara: nuevos datos documentales", Monte Carmelo, XCII, Burgos, 1984, pp. 429-439.

Arch. esp. arte, LXXXVII, 345, ENERO-MARZO 2014, 65-74

ISSN: 0004-0428, eISSN: 1988-8511, doi: 10.3989/aearte.2014.05 
Muñoz Jiménez, José Miguel, La arquitectura del Manierismo en Guadalajara, Guadalajara, Excma. Diputación Provincial de Guadalajara-Institución Provincial de Cultura "Marqués de Santillana", 1987.

Muñoz Jiménez, José Miguel, "Fray Alberto de la Madre de Dios y la arquitectura cortesana: urbanismo en la villa de Lerma", Goya, 211-212, Madrid, 1989, pp. 52-59.

Muñoz Jiménez, José Miguel, "Sobre la formación y significación del arquitecto montañés fray Alberto de la Madre de Dios", Altamira, XLVIII, Santander, CSIC, 1989, pp. 65-90.

Muñoz Jiménez, José Miguel, Fray Alberto de la Madre de Dios, arquitecto (1575-1635), Santander, Ediciones Tantín, 1990.

Muñoz Jiménez, José Miguel, La arquitectura Carmelitana (1562-1800). Arquitectura de los carmelitas descalzos en España, México y Portugal durante los siglos XVI a XVIII, Ávila, Diputación Provincial de Ávila-Institución Gran Duque de Alba, 1990.

Muñoz Jiménez, José Miguel, “Diccionario de Artífices del Carmelo Descalzo”, Monte Carmelo, C, Burgos, 1992, pp. 49-78.

Muñoz Jiménez, José Miguel, “Adenda al Diccionario de Artífices del Carmelo Descalzo: arquitectos, maestros de obras y ensambladores", Monte Carmelo, CIX, Burgos, 2001, pp. 479-489.

Muñoz Jiménez, José Miguel, "Segunda adenda al Diccionario de Artífices del Carmelo Descalzo: arquitectos, maestros de obras, ensambladores y oficiales", Monte Carmelo, CXXI, Burgos, 2013, pp. 269-304.

Nieto Gallo, Gratiniano, Los monumentos de Lerma. Paradigma de la arquitectura post-escurialense, Madrid, Universidad de Madrid, 1959.

Pérez Bustamante, C., "Los cardenalatos del Duque de Lerma y del Infante don Fernando de Austria", Boletín de la Universidad de Santiago de Compostela, 24, Santiago de Compostela, 1935, pp. 19-74.

Ponz, Antonio, Viage de España, en que se da noticia de las cosas más apreciables y dignas de saberse que hay en ella, XVI, Madrid, Joaquín Ibarra, 1791.

Sánchez Belén, Juan Antonio, "Fernando de Austria. El Cardenal Infante", en Aldea Vaquero, Quintín (coord.), Diccionario Biográfico Español, VI, Madrid, Real Academia de la Historia, 2010, pp. 107-111.

Tovar Martín, Virginia, "Presencia del arquitecto Fray Alberto de la Madre de Dios en Madrid y en Guadalajara", Anales del Instituto de Estudios Madrileños, XVI, Madrid, 1979, pp. 85-96.

Tovar Martín, Virginia, Arquitectura madrileña del s. XVII (datos para su estudio), Madrid, Instituto de Estudios Madrileños, 1983.

Tovar Martín, Virginia, "Lo escurialense en la arquitectura madrileña del siglo XVII” en Campos y Fernández de Sevilla, Francisco Javier (Coord.), El Monasterio de El Escorial y la arquitectura: actas del simposium, Madrid, Real Centro Universitario Escorial-María Cristina, 2002, pp. 285-312.

Verdú Berganza, Leticia, La “arquitectura carmelitana” y sus principales ejemplos en Madrid (siglo XVII). 3 tomos (Tesis doctoral inédita). Madrid, Universidad Complutense de Madrid, 1996.

Fecha de recepción: 28-VI-2012

Fecha de aceptación: 17-X-2013

Arch. esp. arte, LXXXVII, 345, ENERO-MARZO 2014, 65-74

ISSN: 0004-0428, eISSN: 1988-8511, doi: 10.3989/aearte.2014.05 